\title{
Graphic Art Design Combining Chinese Traditional Culture with International Cultural Elements
}

\author{
Zhang Mo \\ Chengdu Neusoft University, Chengdu, Sichuan, China, 611844
}

Keywords: Chinese traditional culture; international cultural elements; graphic art design

\begin{abstract}
When Chinese traditional culture is used in graphic art design, the form usually used is diversification. Chinese traditional culture has a long history and profound cultural heritage, which requires writing and patterns, ideas and styles, artistic design, calligraphy and seal carving. Imagery and figuration are combined to form a diversified structural form, which will deepen the cultural heritage to a certain extent, strengthen the design of visual appeal and the extension of design ideas, and ultimately show the historical characteristics and aesthetic perspective of national culture. The application of Chinese traditional culture to graphic design can reflect its advantages, combine the development of international culture, and combine Chinese traditional culture with international cultural elements to design high-quality graphic arts.
\end{abstract}

\section{Introduction}

Chinese culture has a long history, extensive and profound. It has 56 ethnic groups. Each ethnic group has its own cultural elements, and elements of different types constitute cultural elements with ethnic characteristics. China has continued several generations of ethnic elements and laid the foundation for artistic innovation. In the course of graphic art design, some ethnic elements can be added, highlighting the design style with ethnic characteristics. In the life, it uses the national culture, abstracts the national elements, and has visual features.

\section{Origin and Problems of Graphic Art Design}

Some scholars believe that it is possible to solve the difficult issues through the importance and significance of philosophy. Art is the core content of philosophy. What problems will be encountered in the design of modern art? In recent years, with the continuous deepening of reforms, China's current design education and modern art have been innovated to conform to the trend of the times. Because China's mentality in development has not been stable, leading to the modern graphic design has been changing according to changes in the market economy, there are a series of problems. With the continuous development of China's economic construction, people's quality of life has been greatly improved, and people's aesthetic vision has also gradually improved, but it has not changed the current state of development. In the domestic graphic design industry, some new and traditional elements will be added [1]. However, there are few works that combine the modern design with the decorative patterns of Chinese traditional elements, and even there will be plagiarism. There are many bad social trends. Facing this kind of situation, it brings serious decline to the graphic design industry. The relationship between people and design, and the relationship between design and products are based on commercial interests. In this regard, under the monopoly market of internationalism, China's graphic arts have also risen, and there has often been a phenomenon of neglecting the traditional culture of the nation. The domestic design language is relatively monotonous. This is not the same as the design style of international diversity. Once this phenomenon is stopped at the surface, it will not only be of no help in attracting foreign cultures, but will also have no effect on inheriting traditional culture. It may also lead to a shortage of design language, which will have a serious impact on the development history and trend of the later stage of graphic art design. In the graphic art design, it is necessary to attach great importance to independence and far-reachingness. Under the premise of international design style, attention is 
paid to the development of traditional Chinese national culture. Applying traditional decorative patterns to modern graphic design not only breaks through the monotonous form of international monopoly graphic design, but also exacerbates the sense of belonging and recognition among various ethnic groups. It plays a crucial role in embodying ethnic characteristics, graphic art design features, and creating new modern graphic designs.

\section{Development Strategy of Graphic Art Design}

Under the new situation, graphic design plays a dominant role in the development and continuation of art. The in-depth study of artistic continuation and development strategies is currently the core content of graphic art design work and plays an extremely important role in improving the level of artistic design. In the continuation of graphic art design, not only should the bottom line thinking be put in the first place, but also the core elements of the Chinese nation should be preserved and the independence of culture should be highlighted. At the same time, we must maintain the openness and inclusiveness of art, draw on different types of artistic elements, and combine different types of cultural elements with national cultural systems to fundamentally improve the scope of application and application of graphic art design. Depth and development level. Under the premise of historical development, the vitality of traditional Chinese cultural elements will be enhanced and the sustainable development of national art design will be promoted. For creative materials, Chinese national elements mainly include historical and cultural materials. These creative materials and creative resources have laid a solid foundation for the creative development of graphic art design. After imitating the arts, the content was innovated in the graphic design. In the process of creating the national elements, many good works are imitating the traditional art methods and become their own art form. For continuation and integration, modern graphic technology adopts its essence and integrates with its own cultural characteristics, [2] and thus completes more design works. This will not only enrich its own art form, but also reflect the characteristics of traditional culture, promote the rapid development of graphic arts, and provide guarantee for the establishment of a cultural and artistic system in China.

\section{Application of Chinese Traditional Cultural Elements in Graphic Art Design}

\subsection{Ethnic elements.}

In the graphic art design process, a large number of ethnic elements will be produced, and ethnic elements may also be called Chinese elements. It is not only the representative of traditional Chinese culture, but also the innovation and fashion in graphic art design. In the process of designing modern art and creation, it pays great attention to the national elements, and the ethnic elements that are highly valued by famous scholars, designers, and consumers are the most important. The main ones. At present, modern industrial technology has improved the quality of people's lives. Under the premise of more and more obvious cultural economy and science and technology, it distinguishes cultures of various countries. National culture is its core basis and the key factor in maintaining innovation. In terms of the design of modern Chinese graphic arts, there are still some problems. The history of China has a long history, but it cannot be used and controlled well, and it is impossible to fully display the unique cultural heritage of the nation. [8] Nowadays, despite China's remarkable achievements in design, there are still phenomena of simple invocation and imitation, and it is impossible to fully express the artistic essence of traditional culture. At this time, we must re-recognize and extend Chinese traditional culture, have a deeper understanding of traditional art virtues, provide guarantees for the design of eternal cultural values, and promote the development of globalization.

\subsection{Advertising design elements.}

Graphic art design is very important in the process of advertising design. When designing, advertising must have its own unique design style. In the analysis of color, it is not difficult to see that diversity colors are the characteristics of graphic arts, and the rational use of color will produce 
a visual impact effect to some extent, leaving people with unforgettable memories. Analyzing the frame of the picture, along with the pace of development of the times. The extensibility and innovation are the unique features of the graphic art design, and the precondition for the road to internationalization. In the graphic arts design of the international field, to make graphic art design a place in the market, the staff is required to have an in-depth understanding of Chinese traditional culture and master the essence of it. To design a good graphic art, we must not only rationally use colors and composition, but also master and understand the essence of traditional Chinese national culture. In general, designers should let consumers really understand the essence of Chinese traditional culture. And connotation, create works that consumers like, meet the aesthetic requirements of consumers, and then adjust and analyze according to the direction of internationalization. In China, there are many cultural elements with strong ethnic characteristics. For example, paper-cutting and New Year pictures depicting the classical beauty of traditional culture; ethnic elements with different era characteristics, such as Tang Sancai, Peking Opera mask and Chinese calligraphy, can be combined with international cultural elements. [3]

\section{Analysis of the Missing and Return Factors of Ethnic Elements in Graphic Arts}

In the process of Chinese graphic art design, it often appears that the works of Chinese designers have been taken abroad, and at the same time, there is no indication that they are works designed by Chinese designers. Many foreign designers have a special liking for Chinese traditional culture. In addition, most designers feel that Chinese traditional culture is relatively conservative, but foreign designers are seen as fashionable when they use it. This requires us to pay attention to the return of national elements of our country. The key factor in this situation is that many Chinese designers frequently use foreign design elements and create attachments. [10] In China, there are many artists and designers who want to create works that are in line with the development of the domestic market in their artistic creation. What is the market situation? What kind of works do foreign consumers need? To design a work that meets the requirements. In the creation, the essence of the national culture was not displayed, and the phenomenon of worshipping foreign affairs was severely cracked down. With the development trend of economic globalization, the situation is now very dangerous. People's traditions have not disappeared, and they have not used the self-closed approach to maintain the national culture. It is necessary to use the characteristics of traditional national culture to tap into the relevant modern culture further deepens the understanding and exploration of ethnic cultures and thus protects traditional Chinese culture. In Chinese graphic art design, designers must correctly master the subtleties of culture, create works that meet the characteristics of the country, and promote the development of Chinese culture toward the international market. [4]

\section{The Internationalization and Localization of Ethnic Elements}

Particularity and representativeness are characteristics of ethnic culture. However, if we want to gain a foothold in the international market, we must also have publicity and partnership, and finally be adopted and recognized by people. In the graphic art design, traditional Chinese national culture is its core. Once there is no support and assistance from traditional Chinese culture, the development of graphic art design becomes very difficult. Therefore, in the design of graphic arts, designers must pay attention to ethnic elements. Only by designing good graphic artwork can they be promoted in the world design stage and be more recognized and valued by the Chinese people. A solid foundation is laid for the artistic development of culture. [7] In addition, the essence of traditional cultural elements must be used and combined with international cultural elements. Judging from the current state of development, in conjunction with international cultural elements, the traditional Chinese graphic arts of the traditional culture will have some problems in the design process. Some works follow the Western countries' design ideas and design framework, leading to graphic art design. Lack of national cultural essence has made China's graphic art design lose its competitiveness in the world design stage. Excessive pursuit and use of the design ideas of Western 
countries is an extremely irrational act, which will cause the country's graphic design to lose its color and foundation, and lack particularity and nationality. At present, Chinese designers gradually use the elements of their own countries to gain an in-depth understanding of Chinese elements and apply them to graphic art design work to improve China's position in international history. Nowadays, many graphic designs in China have traditional cultures. For example, in the early stage of the 2008 Beijing Olympic Games, the design mascot Fuwa was the reference panda and Tibetan antelope, and the Olympic Torch was the reference to the cloud pattern. [5] In the 2012 Shanghai World Expo, China's traditional cultural elements were also integrated into it, creating a unique graphic design in China.

\section{National and International Integration Methods}

There is a gap between the cultural background and social background of the East and West, and there is a different course of development in the graphic design process. This has different advantages and characteristics, and the two do not affect each other. Integrate the traditional culture, find its essence, continue to learn advanced foreign graphic design principles, strictly prohibit the appearance of plagiarism, and combine international trends, nationalities, traditional arts, and cultural appreciation. In addition, in the path to internationalization, we must demonstrate a cultural element with national characteristics. The world civilization is to be established by the entire nation. When designing the Chinese plane, it must be carried out on the basis of globalization to create cultural designs with national characteristics. In this regard, we must use an objective and scientific approach to view the relationship between nationality and internationalization. While continuing to pursue the psychological quality of the nation, we must also have an in-depth understanding of the subtleties of international culture and advance with the world. The sustainable development of Chinese graphic arts design, as well as the key factors in promoting national characteristics and leading the world design trend. The American Times reporter once said that the Chinese brand logo is the same as that of the Nazi SS. Although there is no apparent plagiarism in China's graphic design, everyone can also know that Chinese designers have not fully understood the resources of graphic design culture and mastered the world language. However, there are still many excellent designers in the field of modern graphic design. They also have many excellent works, such as the famous Hong Kong designer Mr. Jin Daiqiang. His works show the most vivid expression of traditional culture. The design symbol of the Bank of China is from Mr. Jin Daiqiang's hands, it is based on Chinese ancient characters and coins. Its expression is abstract, simple, and rich in content. It is a dignified and generous party, an inner circle and an elegant style. It perfectly embodies the national characteristics. In addition, there must be an international aesthetic concept. [6] For example, the designer of the 2008 China Olympics logo was a famous domestic designer, Mr. Chen Shaohua. The logo was based on the Olympic rings, evolved into five interdependent five-colored five-pointed stars, and was playing Tai Chi. It is very similar to fully demonstrate the plot of Chinese traditional culture. The unity, development, communication, and collaboration of the five continents are the core of the work, revealing the essence of Chinese traditional sports culture and giving China's successful bid for the Olympic Games. [9]

\section{Conclusion}

In summary, with the continuous development of China's economy, it has also promoted the development of traditional Chinese culture to some extent. Our country is influenced by western culture more profoundly. To this end, we need to build on the basis of modern and traditional, Chinese and Western, and national and ethnic groups to strengthen the exchange and communication between Chinese traditional culture and international cultural elements. In international graphic arts design, the works with ethnic characteristics will be displayed and the status of our culture in the international market will be maintained. In this regard, graphic arts design staff must continue to work harder to innovate and design better works. 


\section{References}

[1] Gong Minmin. The Fusion of Chinese Traditional Culture and International Cultural Elements in Graphic Art Design [J]. Writer, 2015, (14): 221-222.

[2] Jiang Zaozao. The Reference and Inheritance of the Traditional Culture of Graphic Art Design in the New Era [J]. Art Fashion Weekly, 2014, (8): 89-90.

[3] Lu Jinzhuo. Analysis of the Application of Chinese Traditional Culture and Art Elements in Modern Graphic Design [J]. Art, 2016, (11): 279-280.

[4] Yang Lei. Application of Chinese Traditional Culture and Art Elements in Modern Graphic Design [J]. Modern Communication, 2016, (5): 76-78.

[5] Wang Yan. Research on the Application of Chinese Traditional Painting Elements in Modern Print Design [J]. Northwest Normal University, 2014

[6] Zhao Minda. Ink of the New Melody - A Brief Discussion on the Traditional Aesthetic Appreciation of Ink Painting Applied in Graphic Design [J]. Art and Design, 2014, (7): 31-33.

[7] Leng Zenglong. Analysis of the Influence of Chinese Traditional Culture on Graphic Design[J]. Studies of Fine Arts Education, 2015, (12):53-54.

[8] Wang Guannan. Analysis of the Influence of Chinese Traditional Culture on the Design Basis of Chinese and Western Combination [J]. Artwork Kam, 2016, (8):

[9] Hua Bing. On the Inheritance and Innovation of Folk Art Forms in Graphic Design [J]. Shen Zhou, 2013, (3): 197-198.

[10] Zhu Ming. The application of traditional cultural elements in indoor and outdoor design [J]. Art Fashion Weekly, 2014, (11): 206-207. 